\title{
"EXCITONIC" AND PHOTOIONIZATION ABSORPTION SPECTRA OF IRON IN III-V MATERIALS
}

\author{
A. Wysmolek, R. Tryc, R. Bożek and A.M. Hennel \\ Institute of Experimental Physics, Warsaw University \\ Hoża 69, 00-681 Warszawa, Poland
}

\begin{abstract}
We report optical absorption measurements of Fe-doped GaAs, InP and $\mathrm{GaP}$ crystals obtained with the help of different doping techniques. In all these crystals photoionization spectra corresponding to $\mathrm{Fe}^{3+} \rightarrow \mathrm{Fe}^{2+}$ transitions with sharp "excitonic" lines were observed. The intensities of these lines are not proportional to the intensities of photoionization absorption bands, i.e. to the concentration of the $\mathrm{Fe}^{3+}$ centers. Variation of more than one order of magnitude was observed for different semiconductors and for different crystals of the same material. These results suggest that only some iron centers are responsible for the "excitonic" spectra.

PACS numbers: $71.55 . \mathrm{Eq}, 78.55 . \mathrm{Cr}$
\end{abstract}

\section{Introduction}

The optical properties of iron impurity in InP, GaAs and GaP crystals have been investigated for many years. There are three review articles devoted to this subject [1-3]. Several new papers [4-12] published recently have brought new information about the $\mathrm{Fe}^{3+}\left(3 d^{5}\right) \rightarrow \mathrm{Fe}^{2+}\left(3 d^{6}\right)$ photoionizing transitions in these materials. Sharp "excitonic" structures of the photoionization bands reveal distances of the $\mathrm{Fe}^{2+}\left(3 d^{6}\right)$ intracenter transition zero-phonon lines within $0.1 \mathrm{~cm}^{-1}$ accuracy. These spectra were investigated with the help of calorimetric-absorption spectroscopy (CAS) $[4,5]$, magnetic circular dichroism (MCD) [6, 7], Fourier-transform spectroscopy (FT) [8-11] and conventional absorption spectroscopy (OA) [12].

This paper reports absorption measurements of the $\mathrm{Fe}^{3+}\left(3 d^{5}\right) \rightarrow \mathrm{Fe}^{2+}\left(3 d^{6}\right)$ transition in $\mathrm{GaAs}, \mathrm{GaP}$ and InP crystals obtained with the help of different doping techniques.

\section{Experimental}

We have studied more than 10 different Fe-doped, semi-insulating (SI) liquid encapsulated Czochralski (LEC) InP, GaP and GaAs crystals and Fe-diffused $\mathrm{GaAs}$ and $\mathrm{GaP}$ crystals. Absorption measurements were performed at about $10 \mathrm{~K}$ between 0.8 and $3 \mu \mathrm{m}$ with the help of a Cary 5 UV-VIS-NIR spectrometer. 


\section{Results and discussion}

In all these crystals, nearly identical photoionization spectra corresponding to the already reported $\mathrm{Fe}^{3+} \rightarrow \mathrm{Fe}^{2+}\left({ }^{5} E\right)$ and $\mathrm{Fe}^{3+} \rightarrow \mathrm{Fe}^{2+}\left({ }^{5} T_{2}\right)$ transitions were observed, as shown in Fig. 1. The only differences between the spectra in these materials are their energy positions. The first $\mathrm{Fe}^{3+} \rightarrow \mathrm{Fe}^{2+}\left({ }^{5} E\right)$ transition starts at $0.49 \mathrm{eV}$ in GaAs, at $0.78 \mathrm{eV}$ in InP and $0.82 \mathrm{eV}$ in GaP. The second $\mathrm{Fe}^{3+} \rightarrow$ $\mathrm{Fe}^{2+}\left({ }^{5} T_{2}\right)$ transition starts at $0.87 \mathrm{eV}, 1.14 \mathrm{eV}$ and $1.23 \mathrm{eV}$, respectively.
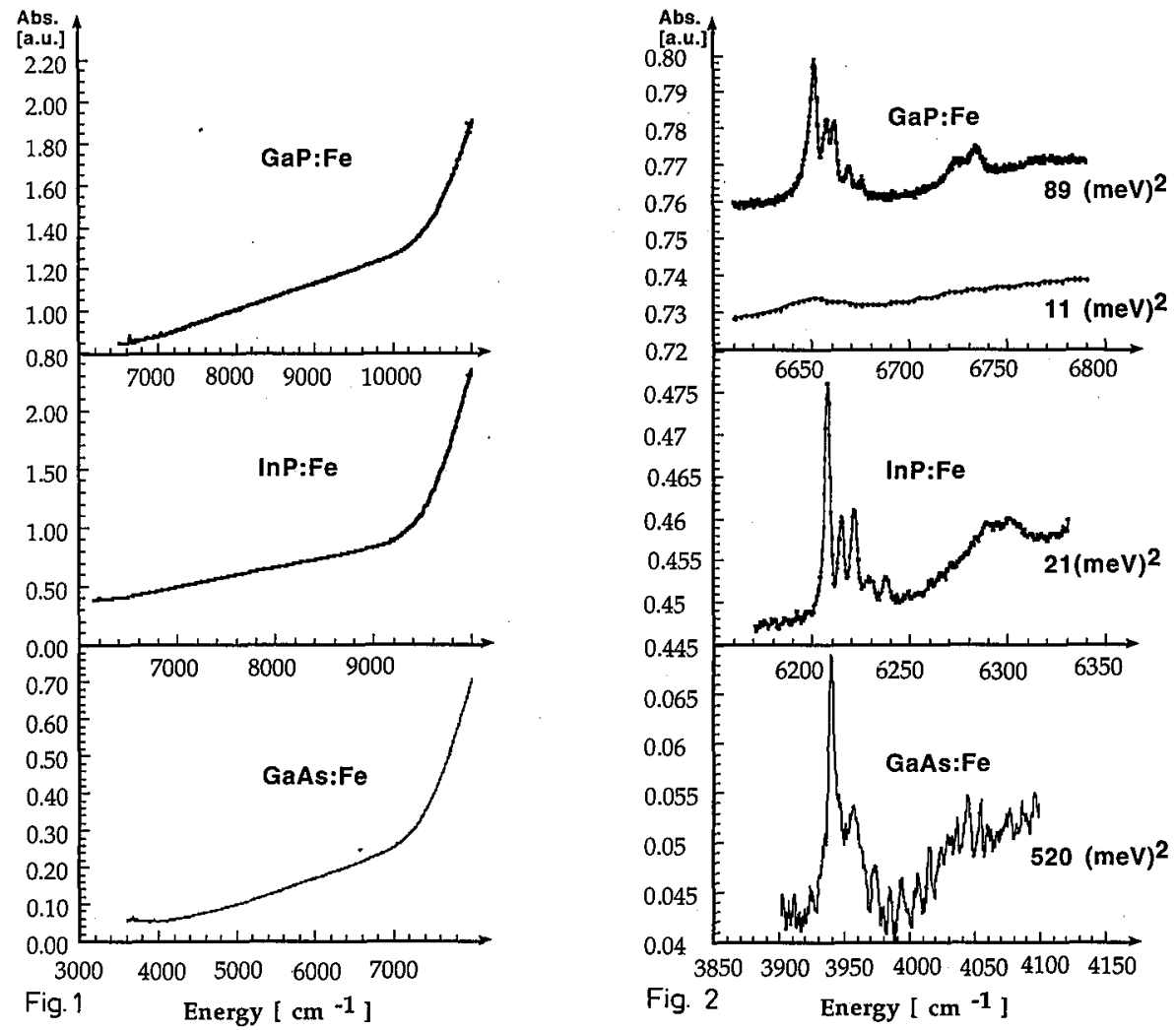

Fig. 1. Absorption photoionization spectra of the $\mathrm{Fe}^{3+} \rightarrow \mathrm{Fe}^{2+}\left({ }^{5} E\right)$ and $\mathrm{Fe}^{3+} \rightarrow$ $\mathrm{Fe}^{2+}\left({ }^{5} T_{2}\right)$ transitions in III-V semiconductors obtained at about $10 \mathrm{~K}$.

Fig. 2. Sharp "excitonic" structures (so called a'-e' lines) at the beginning of the $\mathrm{Fe}^{3+} \rightarrow \mathrm{Fe}^{2+}\left({ }^{5} E\right)$ transitions in III-V semiconductors. The numbers on the right side represent the ratio of their intensity to the slope of the photoionizing transition.

At the beginning of these transitions several authors found a number of sharp "excitonic" lines [4-12]. We observed all the lines previously reported. There are theoretical models available, which try to explain these results as excitons bound to the iron impurity, optical transitions from the valence band to the $\mathrm{Fe}^{2+}$ charge state or transitions generating an effective-mass like bound hole. All these 
interpretations of the sharp structures assume that their intensity is proportional to the intensity of the photoionization absorption bands, i.e. to the concentration of the $\mathrm{Fe}^{3+}$ centers.

To check this assumption, we chose the strongest, first group of lines (Fig. 2), so called a'-e' lines, and calculated the ratio of their intensity to the slope of the first photoionizing transition. We find that this ratio varies very strongly for different semiconductors and even for different crystals of the same material. It is equal to about $500 \mathrm{meV}^{2}$ for GaAs crystals, about $20 \mathrm{meV}^{2}$ for InP and varies from $10 \mathrm{meV}^{2}$ for diffused samples to $90 \mathrm{meV}^{2}$ for melt doped $\mathrm{GaP}$ crystals.

In our opinion this result suggests that only some iron centers are responsible for the "excitonic" spectra, and that their concentration depends on the doping technique. In this situation the above-mentioned models should be reconsidered.

\section{Acknowledgments}

The authors are deeply indebted to Dr. G. Iseler from the Lincoln Laboratory of the Massachusetts Institute of Technology (Cambridge, MA, USA), Dr. M. Baumgariner from Wacker-Chemitronics (Burghausen, Germany), Prof. W. Ulrici from the Paul-Drude-Institut für Festkörperelektronik (Berlin, Germany) and Dr. A. Hruban from the Institute of Electronics Materials Technology (Warsaw) for supplying us with the GaAs, GaP and InP crystals. This work was supported by the the Committee for Scientific Research grant No. 201799101.

\section{References}

[1] S.G. Bishop, in: Deep Centers in Semiconductors, Ed. S. Pantelides, Gordon and Breach Science, New York 1986, p. 541.

[2] B. Clerjaud, J. Phys. C, Solid State Phys. 18, 3615 (1985).

[3] A.M. Hennel, in: Imperfections in III-V Materials, Ed. E. Weber; in series Semiconductors and Semimetals, Eds. R.K. Willardson, A.C. Beer, Vol. 38, Academic Press, in press.

[4] A. Juhl, A. Hoffmann, D. Bimberg, H.J. Schulz, Appl. Phys. Lett. 50, 1292 (1987).

[5] T. Wolf, D. Bimberg, W. Ulrici, Phys. Rev. B 43, 10004 (1991).

[6] A. Görger, B.K. Meyer, J.-M. Spaeth, in: Semi-Insulating III-V Materials, Malmö 1988, Eds. G. Grossmann, L. Ledebo, Adam Hilger, Bristol 1988, p. 331.

[7] A. Görger, J.-M. Spaeth; Semicond. Sci. Technol. 6, 800 (1991).

[8] K. Pressel, K. Thonke, A. Dörnen, in: Physics of Semiconductors, Eds. E.M. Anastassakis, J.D. Joannopoulos, World Scientific, Singapore 1990, p. 690.

[9] K. Thonke, K. Pressel, Phys. Rev. B 44, 13418 (1991).

[10] A.M. Hennel, A. Wysmołek, R. Bozek, D. Côte, C. Naud, in: Defects in Semiconductors, Eds. G. Davies, G.G. DeLeo, M. Stavola, Material Science Forum 83-87, 729 (1992).

[11] K. Pressel, G. Rückert, K. Thonke, A. Dörnen, in: Defects in Semiconductors, Eds. G. Davies, G.G. DeLeo, M. Stavola, Material Science Forum 83-87, 695 (1992).

[12] A. Wysmołek, A.M. Hennel, Acta Phys. Pol. A77, 67 (1990). 